\title{
One-Step Synthesis of Hyperbranched Polyesters. Molecular Weight Control and Chain End Functionalization
}

\author{
K. L. WoOley, ${ }^{\dagger}$ C. J. HaWker, ${ }^{\dagger \dagger}$ R. Lee, and J. M. J. FréCHeT* \\ Department of Chemistry, Baker Laboratory, Cornell University, \\ Ithaca, N.Y. 14853-1301, U.S.A.
}

(Received July 23, 1993)

\begin{abstract}
A new procedure is described for the preparation of chloride ion free 3,5-bis(trimethylsiloxy)benzoyl chloride, which allows the reproducible preparation of hyperbranched aromatic polyesters with controllable molecular weights. The pure monomer is thermally stable at temperatures of more than $200^{\circ} \mathrm{C}$, but is readily polymerized when heated in the presence of catalytic amounts of dimethylformamide or trimethylamine hydrochloride. The molecular weight of the polymers increases with higher reaction temperatures, longer reaction times, and larger amounts of catalyst. Polymerizations in $o$-dichlorobenzene also afford similar results. The hyperbranched polyesters have degrees of branching of $c a .60 \%$ and contain a large number of free phenolic groups both at the chain-ends and in "linear" portions of the chains. Functionalization of these free phenolic hydroxyls is readily accomplished in homogeneous solution. However, reactions with solid $\mathrm{Pd} / \mathrm{C}$ catalyst were not possible. The solubility and thermal properties of the resulting blocked hyperbranched aromatic polyesters reflect the choice of hydroxyl protecting group.

KEY WORDS Hyperbranched / Polyesters / Chemical Modification / Phenolic-Terminated / 3,5-Bis(trimethylsiloxy)benzoyl Chloride /
\end{abstract}

Hyperbranched macromolecules are highly branched, highly functionalized, three-dimensional globular polymers that can be prepared by the one-step polycondensation of $\mathrm{AB}_{x}$ monomers. The versatility of this approach is demonstrated by the numerous examples of hyperbranched materials which have been recently reported. Variations in the A and $\mathrm{B}$ functionalities as well as the monomer structure have led to hyperbranched polyphenylenes, ${ }^{1,2}$ polyesters, ${ }^{3-5}$ polyethers, ${ }^{6}$ polyether ketones, ${ }^{7,8}$ polyamides, ${ }^{9}$ polysiloxanes, ${ }^{10}$ and polyamines. ${ }^{11}$

Hyperbranched structures may be considered as irregular analogs of the dendritic macromolecules that are both monodisperse and uniformly branched. While the synthetic methodologies in the preparation of dendritic macronomolecules allow for a high degree of control over the entire architecture, the organization and connectivity of hyperbranched structures is less controlled and less specific. However, several of the unusual properties of dendritic macromolecules, such as low viscosity, high solubility, and lack of significant entanglement in the solid state, are also exhibited by hyperbranched materials. The one-step polymerization processes used to produce hyperbranched polymers are advantageous when compared to the multi-step syntheses of dendrimers, as they are capable of the rapid production of large quantities of highly-functionalized globular polymers. Therefore, hyperbranched polymers are better suited for applications that exploit the bulk-material properties and that benefit from

* To whom correspondence should be addressed.

$\dagger$ Present address: Washington University, Department of Chemistry, St. Louis, MO 63130-4899, U.S.A.

${ }^{\dagger \dagger}$ Present address: IBM Almaden Research Center, San Jose, CA 95120, U.S.A. 
the presence of a large number of functional sites within a compact space.

We have reported ${ }^{3}$ the condensation of 3,5-bis(trimethylsiloxy)benzoyl chloride 1 to give polyphenol-terminated hyperbranched polyesters 2. However, the thermal stability of the monomer was low, as small amounts of chloride ion impurities present at levels not readily detectable by standard spectroscopic techniques would catalyze its spontaneous polymerization at elevated temperatures. In addition, the presence of some polymerization catalyst within the monomer detracted from our ability to control its polymerization. In particular, the reproducible preparation of hyperbranched polyesters with molecular weights in the range 20000-100000, for comparison of properties with analogous regular dendritic polyesters ${ }^{12}$ proved elusive. Though monomer purification could be attempted, the yield of purified monomer was unacceptably low.

The preparation of pure, thermally stable 3,5-bis(trimethylsiloxy)benzoyl chloride, $\mathbf{1}$, is now reported. The seemingly slight, but significant modifications in the synthesis gave a higher yield of $\mathbf{1}$ and provided a pure monomer suitable for polymerization with control over molecular weight. The polymerization process itself involved catalysis with either trimethylamine hydrochloride or $N, N$ dimethylformamide. Control of the molecular weight of the resulting hyperbranched polymer was achieved by regulating the amount of catalyst, ${ }^{13}$ the reaction temperature, and the reaction time. The chemical reactivity of the phenolic chain ends was also demonstrated through several chemical modification reactions.

\section{RESULTS AND DISCUSSION}

\section{Monomer Synthesis}

The preparation of the monomer, 3,5-bis(trimethylsiloxy)benzoyl chloride $\mathbf{1}$, is shown in Scheme 1. In this approach, chloride ion sources were avoided by the use of hexamethyldisilazane (HMDS) for silylation and $N, N$-dimethylformamide (DMF) as a catalyst for acid chloride formation. Reaction of $\mathbf{3}$ with neat HMDS gave trimethylsilyl 3,5-bis(trimethylsiloxy)benzoate, 4 , in $94 \%$ yield after purification. Preparation of the acid chloride 1 from the trimethylsilyl ester was attempted initially as reported by Kricheldorf ${ }^{11}$ for the preparation of 4-trimethylsiloxybenzoyl chloride. However, the reaction of $\mathbf{4}$ with thionyl chloride in benzene heated at reflux was unsuccessful. Monitoring of the reaction by ${ }^{1} \mathrm{H}$ NMR showed that only $23 \%$ of 1 was formed after 7 days in refluxing benzene in the absence of catalysts. After addition of a catalytic amount of DMF, the reaction proceeded to $80 \%$ completion in $6 \mathrm{~h}$. Optimum conditions included the use of a mixture of 4 with an excess of thionyl chloride (1.2 eq) and a catalytic amount of DMF $(0.3 \mathrm{~mol} \%)$ in benzene at reflux. Work-up of the reaction mixture, by filtering through a column of alumina under argon followed by vacuum distillation, gave the acid chloride 1 in $75 \%$ yield.

Monomer prepared by this procedure was not only obtained in fairly high yield, but it also showed excellent thermal stability. Heating neat 1 at $220^{\circ} \mathrm{C}$ for several hours did not cause any polymerization or decomposition. The absence of polymerization-initiating impurities allowed a study of the effect of polymerization conditions on molecular weight.

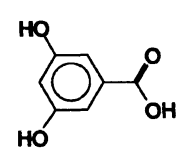

3

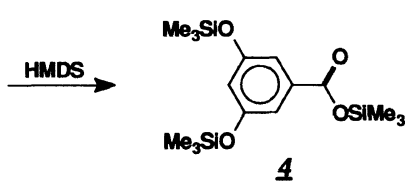

Scheme 1.

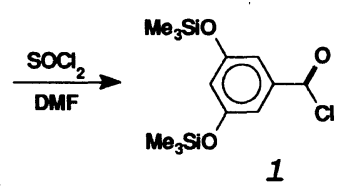

1 


\section{Polymerization}

Four important variables were studied in the polymerization of $\mathbf{1}$ : reaction temperature; reaction time; nature and amount of catalyst. The polymerizations (Scheme 2) were conducted on neat monomer, $\mathbf{1}$, containing catalyst under a stream of nitrogen as outlined in Table I. During polymerization, the release of chlorotrimethylsilane was observed as effervescence from the reaction mixture, while the reaction mixture became increasingly viscous. Because the glass transition temperature of the trimethylsilyl analog of 2 is $c a .150^{\circ} \mathrm{C}$, the polymerizations were done at temperatures to allow the reaction to proceed in the melt, thereby providing greater mobility and flexibility for the growing hyperbranched polymers. Reaction temperatures of $190-200^{\circ} \mathrm{C}$ generally gave products with higher molecular weights than were obtained from reactions at lower temperatures, all other variables being held constant (Table I). Temperatures higher than $220^{\circ} \mathrm{C}$ gave colored products and, therefore, were not used.

Based on the results of our previous study, trimethylamine hydrochloride was the first polymerization catalyst investigated. $N, N-$
Dimethylformamide is also an active catalyst for the polymerization and has the advantage of affording a one-phase, liquid reaction misture which provides for better mixting of catalyst with monomer and leads to more reproducible results. Overall, the effect of catalyst concentration on the molecular weight is small. In general, higher catalyst concentrations provice higher molecular weight polymers, but this effect is less significant than that of reaction times and reaction temperatures. As expected, longer reaction times allowed for further growth and the production of higher molecular weight products.

As is the case in most polycondensations of this type, formation of high molecular weight hyperbranched polymers is enhanced ${ }^{14}$ by the use of high vacuum to remove the chlorotrimethylsilane by-product as it is formed. However, this study was carried-out under nitrogen atmosphere to avoid loss of reproducibility due to slight variations in vacuum.

Work-up of the hyperbranched polyester initially involved solubilization in a mixture of benzene and pyridine, followed by precipitation into methanol. Since complete removal of the pyridine from the precipitated polymer was

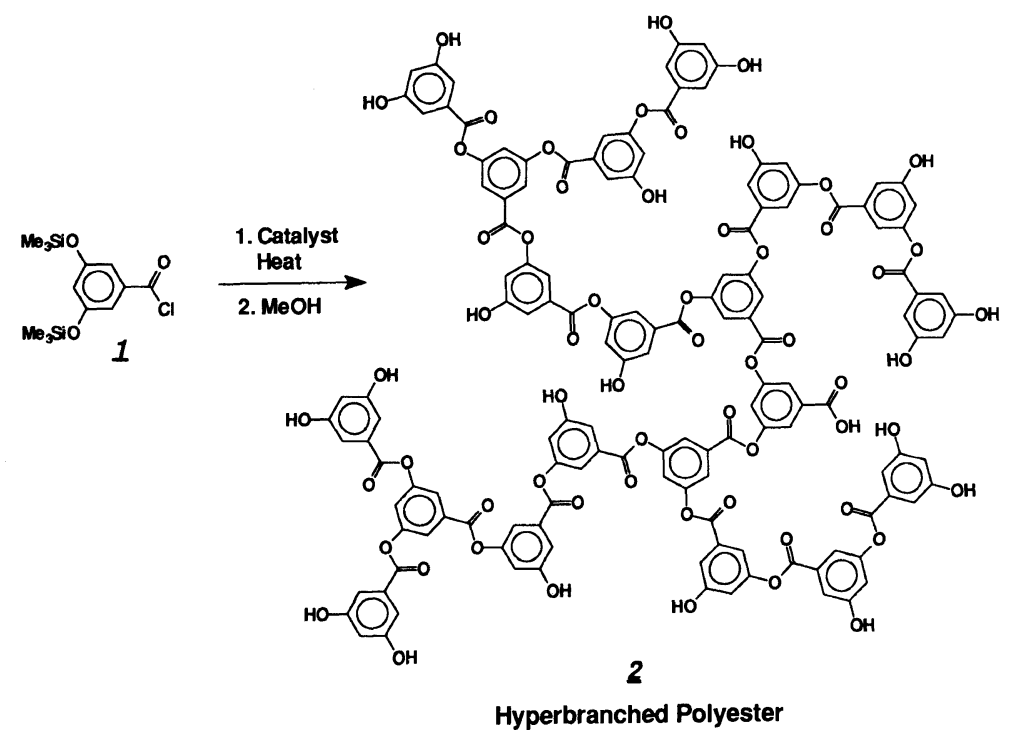

Scheme 2. 
Table I. Preparation of hyperbranched polyesters from polymerization of neat 3,5-bis(trimethylsiloxy)benzoyl chloride under various reaction conditions

\begin{tabular}{|c|c|c|c|c|c|}
\hline Catalyst & $\begin{array}{l}\text { Percent } \\
\text { catalyst }\end{array}$ & $\begin{array}{c}\text { Reaction } \\
\text { temperature }\end{array}$ & $\begin{array}{l}\text { Reaction } \\
\text { time }\end{array}$ & Yield & $M_{w}{ }^{\mathrm{a}}$ \\
\hline \multicolumn{6}{|c|}{ Variation in catalyst amount: } \\
\hline $\mathrm{Me}_{3} \mathrm{NHCl}$ & $\mathbf{0}$ & $200^{\circ} \mathrm{C}$ & 0.5 & - & Monomer \\
\hline $\mathrm{Me}_{3} \mathrm{NHCl}$ & 0.5 & $200^{\circ} \mathrm{C}$ & 0.5 & $66 \%$ & 13000 \\
\hline $\mathrm{Me}_{3} \mathrm{NHCl}$ & 1 & $200^{\circ} \mathrm{C}$ & 0.5 & $73 \%$ & 19000 \\
\hline $\mathrm{Me}_{3} \mathrm{NHCl}$ & 5 & $200^{\circ} \mathrm{C}$ & 0.5 & $70 \%$ & 29000 \\
\hline $\mathrm{Me}_{3} \mathrm{NHCl}$ & 10 & $200^{\circ} \mathrm{C}$ & 0.5 & $71 \%$ & 12000 \\
\hline $\mathrm{Me}_{3} \mathrm{NHCl}$ & 10 & $200^{\circ} \mathrm{C}$ & $1 \mathrm{~h}$ & $71 \%$ & 100000 \\
\hline DMF & $\mathbf{0}$ & $170^{\circ} \mathrm{C}$ & $2 \mathrm{~h}$ & - & Monomer \\
\hline DMF & 0.5 & $170^{\circ} \mathrm{C}$ & $2 \mathrm{~h}$ & $78 \%$ & 15000 \\
\hline DMF & 2 & $170^{\circ} \mathrm{C}$ & $2 \mathrm{~h}$ & $82 \%$ & 18000 \\
\hline \multicolumn{6}{|c|}{ Variation in reaction temperature: } \\
\hline $\mathrm{Me}_{3} \mathrm{NHCl}$ & $1 \%$ & $180^{\circ} \mathrm{C}$ & $1 \mathrm{~h}$ & $76 \%$ & 32000 \\
\hline $\mathrm{Me}_{3} \mathrm{NHCl}$ & $1 \%$ & $185^{\circ} \mathrm{C}$ & $1 \mathrm{~h}$ & $81 \%$ & 37000 \\
\hline $\mathrm{Me}_{3} \mathrm{NHCl}$ & $1 \%$ & $190^{\circ} \mathrm{C}$ & $1 \mathrm{~h}$ & $73 \%$ & 61000 \\
\hline DMF & $2 \%$ & $150^{\circ} \mathrm{C}$ & $2 \mathrm{~h}$ & $66 \%$ & 7900 \\
\hline DMF & $2 \%$ & $170^{\circ} \mathrm{C}$ & $2 \mathrm{~h}$ & $82 \%$ & 18000 \\
\hline DMF & $2 \%$ & $200^{\circ} \mathrm{C}$ & $2 \mathrm{~h}$ & $91 \%$ & 76000 \\
\hline \multicolumn{6}{|c|}{ Variation in reaction time: } \\
\hline $\mathrm{Me}_{3} \mathrm{NHCl}$ & $1 \%$ & $200^{\circ} \mathrm{C}$ & $0.5 \mathrm{~h}$ & $73 \%$ & 19000 \\
\hline $\mathrm{Me}_{3} \mathrm{NHCl}$ & $1 \%$ & $200^{\circ} \mathrm{C}$ & $1 \mathrm{~h}$ & $76 \%$ & 32000 \\
\hline DMF & $2 \%$ & $150^{\circ} \mathrm{C}$ & $\mathbf{2 h}$ & $68 \%$ & 7900 \\
\hline DMF & $2 \%$ & $150^{\circ} \mathrm{C}$ & $13 \mathrm{~h}$ & $79 \%$ & 69000 \\
\hline DMF & $2 \%$ & $200^{\circ} \mathrm{C}$ & $1 \mathrm{~h}$ & $74 \%$ & 22000 \\
\hline DMF & $2 \%$ & $200^{\circ} \mathrm{C}$ & $2 \mathrm{~h}$ & $91 \%$ & 76000 \\
\hline
\end{tabular}

a Obtained from MALLS (multi-angle laser light scattering) in THF with $\mathrm{d} n / \mathrm{d} c=0.240$.

found to be difficult, the benzene/pyridine mixture was replaced by tetrahydrofuran. While dissolution in tetrahydrofuran was slower and required greater dilution, complete removal of the solvent was possible. It was found that if the reaction mixture was allowed to cool to room temperature before the addition of solvent, large amounts of insoluble material were obtained, with higher reaction temperatures giving increasing amounts of insoluble product. These insoluble fractions were believed to be "pseudo-crosslinked" through the formation of strongly hydrogenbonded aggregates. Heating the pseudocrosslinked materials in highly polar, high boiling solvents, such as $N$-methylpyrrolidone (NMP) or DMF, effected breakage of the hydrogen-bonded aggregates to give soluble products.
Addition of the solution of the crude hyperbranched polyester to methanol resulted in its initial precipitation followed by resolubilization of the polymer as a result of hydrolysis of the trimethylsilyl groups. This is in direct contrast to the benzene/pyridine work-up, that gave a methanol-insoluble product. This difference in solubility in methanol is likely due to the ability of pyridine to strongly complex with the phenolic chain ends of the polymer. Evaporation of the methanolic solution of $\mathbf{2}$ followed by precipitation into ether to remove low molecular weight products, and precipitation into hexanes afforded the purified phenolic-terminated polyester, 2, as an off-white solid. The yields of isolated 2 ranged from $60 \%$ to $90 \%$ depending on the specific reaction conditions and work-up procedures. 
Due to the high viscosity of the polymerization mixture during melt polymerization, the polymerization of 1 was also studied in solution (Table II). The solution polymerizations were performed by heating the monomer and catalyst in $o$-dichlorobenzene at reflux under a stream of nitrogen. As with the neat polymerizations, the molecular weights of the polymers increased with increasing amounts of catalyst and with increasing reaction times, while dilution had an adverse effect on molecular weight.

Table II. Preparation of hyperbranched polyesters from polymerization of solutions of 3,5-bis(trimethylsiloxy)benzoyl chloride in $o$-dichlorobenzene catalyzed by trimethylamine hydrochloride

\begin{tabular}{|c|c|c|c|c|}
\hline \multirow{2}{*}{$\begin{array}{l}\text { Monomer/ } \\
\text { Solvent }^{\mathrm{a}}\end{array}$} & $\begin{array}{l}\text { Percent } \\
\text { catalyst }\end{array}$ & $\begin{array}{l}\text { Reaction } \\
\text { time }\end{array}$ & Yield & \multirow{2}{*}{$M_{w}{ }^{\mathrm{b}}$} \\
\hline & $\%$ & $\mathrm{~h}$ & $\%$ & \\
\hline $1: 1$ & 1 & 15 & 83 & 18900 \\
\hline $1: 1$ & 1 & 17 & 85 & 22800 \\
\hline $1: 1$ & 1 & 18 & 72 & 25100 \\
\hline $1: 1$ & 5 & 18 & 75 & 28700 \\
\hline $1: 2$ & 5 & 15 & 68 & 15700 \\
\hline $1: 1$ & 10 & 18 & 72 & 35200 \\
\hline
\end{tabular}

a Weight ratio.

b Obtained from MALLS in THF with $\mathrm{d} n / \mathrm{d} c=0.240$.

\section{Functionalization}

A characteristic of hyperbranched and dendritic structures is that the number of terminal monomer unit equals the number of dendritic (branching) monomer unit plus one. Therefore, there is an average of one chain end per monomer unit, and the composition of the hyperbranched structure may be represented, schematically by single linear units as in Scheme 3. A variety of different functional groups can be introduced into th hyperbranched macromolecules by reaction of their phenolic groups (Scheme 3). Esterification of the $\mathrm{OH}$ groups of $\mathbf{2}$ can be achieved either by the addition of a monofunctional acid chloride to the initial polymerization mixture, or by isolation and purification of $\mathbf{2}$ followed by its modification. For example, heating a $1: 1$ molar mixture of 4- $t$-butylbenzoyl chloride and 1 with DMF $(2 \%)$ at $200^{\circ} \mathrm{C}$ resulted in the isolation of the acylated polymer $5\left(M_{w}=\right.$ $15000, M_{w} / M_{n}=2.2$, by GPC with polystyrene standards). However, the functionalization reactions can be controlled and varied to a greater degree if the phenolic terminated polyester $\mathbf{2}$ is first isolated and purified. Reaction of $2\left(M_{w}=42000\right.$ measured by multi-angle laser light scattering "MALIS") with acetyl chloride (5 eq with respect to polymer repeat unit) in the presence of
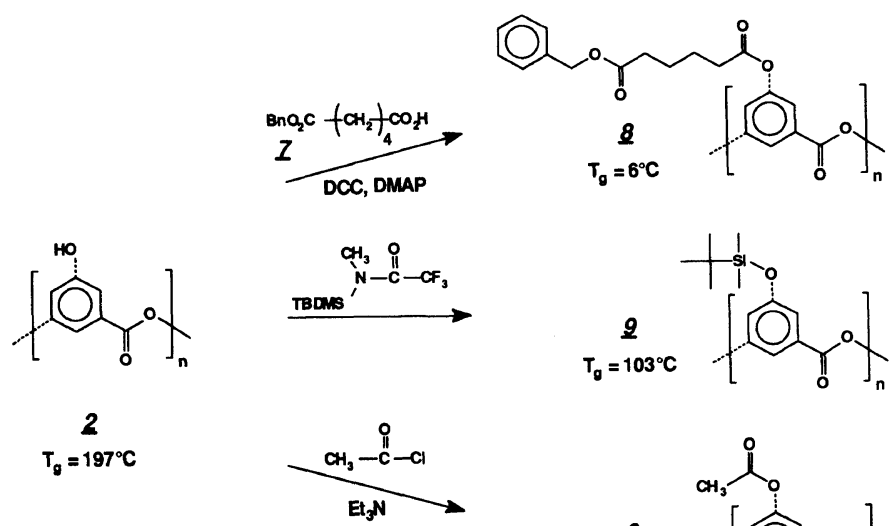

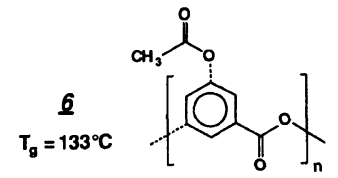

Scheme 3. 
triethylamine gave the fully acetylated hyperbranched polyester, $6\left(M_{w}=46000, M_{w} / M_{n}=\right.$ 2.6 , by GPC with polystyrene standards), in $43 \%$ yield, after precipitation from THF into methanol to remove partially acetylated products. Esterification can also be accomplished through coupling of the phenolic groups of $\mathbf{2}$ with carboxylic acids using DCC/DMAP chemistry. ${ }^{15}$ In the reactions involving DCC (1,3-dicyclohexylcarbodiimide) and DMAP (4-dimethylaminopyridine), it was found that DMAP could only be used in amounts less than $0.1 \mathrm{eq}$. When larger amounts of DMAP were used, the polymer precipitated from solution and reaction did not occur. Precipitation of the polymer likely results from the formation of $\mathrm{H}$-bonded complexes with DMAP, in a similar way to the behavior mentioned earlier for pyridine. Isolation of the precipitate, followed by acidification with glacial acetic acid restored solubility. Addition of DCC to a solution of $2\left(M_{w}=42000\right.$, MALLS) containing monobenzyl adipic acid, 7, and DMAP gave the benzyl ester terminated polyster $\mathbf{8}\left(M_{w}=53000, M_{w} / M_{n}=2.7\right.$, by GPC with polystyrene standards) in $59 \%$ yield with complete functionalization. Silylation of the phenolic groups, for example through reaction with $N$-( $t$-butyldimethylsilyl)- $N$-methyltrifluoroacetamide, also proceeds smoothly to give a stable silyl ether-terminated hyperbranched polyester, $9\left(M_{w}=49000, M_{w} / M_{n}=2.6\right.$, by GPC with polystyrene standards). Finally, reaction of $2\left(M_{w}=3000\right.$, MALLS $)$ with diazomethane in THF at room temperature gave methyl ether-terminated polymer 10 $\left(M_{w}=32000, M_{w} / M_{n}=4.0\right.$, by GPC with polystyrene standards), while in DMF, complete cleavage of the polymer to small molecules occurred, as confirmed both by NMR and GPC, and the appearance of a strong broad band in the IR from $3400-2800 \mathrm{~cm}^{-1}$ and a carbonyl band at 1722 in addition to that at $1744 \mathrm{~cm}^{-1}$. This cleavage is not unexpected in view of the strong basic character of diazomethane in DMF. Interestingly, only partial cleavage is seen in THF and the product is characterized by a broader molecular weight distribution than is the case for other functionalization reactions.

For all functionalization reactions, complete chemical modification was accomplished, indicating that the phenolic chain ends are readily accessible to reagents in solution. However, cleavage of the benzyl groups of the benzyl ester-terminated hyperbranched polyesters, 8, by hydrogenolysis with solid palladium catalysts was not possible. Hydrogenolysis failed using $10 \%$ palladium on carbon with $\mathrm{H}_{2}$ at atmospheric pressure, at pressures of up to $60 \mathrm{psi}$, in various solvents and mixed solvent systems, as well as at elevated temperatures. As determined by ${ }^{1} \mathrm{H}$ NMR spectroscopy, no cleavage of the benzyl groups had taken place. The use of palladium hydroxide on carbon (Pearlman's catalyst) with $\mathrm{H}_{2}$, or $10 \%$ palladium on carbon with cyclohexene as the hydrogen source, also gave no reaction. An analogous behavior has been observed for the benzyl side groups of a linear polymer, while complete debenzylation of a regular dendritic molecule is readily achieved on a catalyst surface as described recently. ${ }^{16}$ We are currently probing this unusual finding correlating the shape, size, or structure of a polymer to its reactivity with a solid surface.

\section{Characterization}

The hyperbranched polyesters were characterized by standard techniques, including ${ }^{1} \mathrm{H}$ and ${ }^{13} \mathrm{C} \mathrm{NMR}$, infrared spectroscopy and gel permeation chromatography, as reported previously. ${ }^{3}$ Not unexpectedly, it has been demonstrated that the polystyrene equivalent molecular weights of dendritic macromolecules ${ }^{17}$ and other highly branched polymers are significantly different from their actual molecular weights. The aromatic hyperbranched polyesters containing large numbers of phenolic chain ends, have the additional problem of affinity with the packing material of the GPC columns, which results in unreliable data. 
Therefore, for all of the phenolic-terminated polymers produced in this study, multi-angle laser light scattering (MALLS) detection was employed to measure their absolute weight average molecular weights as reported in Tables I and II.

Table III reports a comparison of the weight average molecular weights of the phenolic polymers 2 with GPC data (polystyrene standards) obtained for selected functionalized samples containing no free hydroxyls. As can be seen in this table, the method of synthesis we have used provides hyperbranched polymers with a polydispersity between 2 and 3 . This is lower than the values reported by Turner et al. for their very interesting polymers obtained by a different process that affords extremely high molecular weight products.

Although the molecular weight is readily
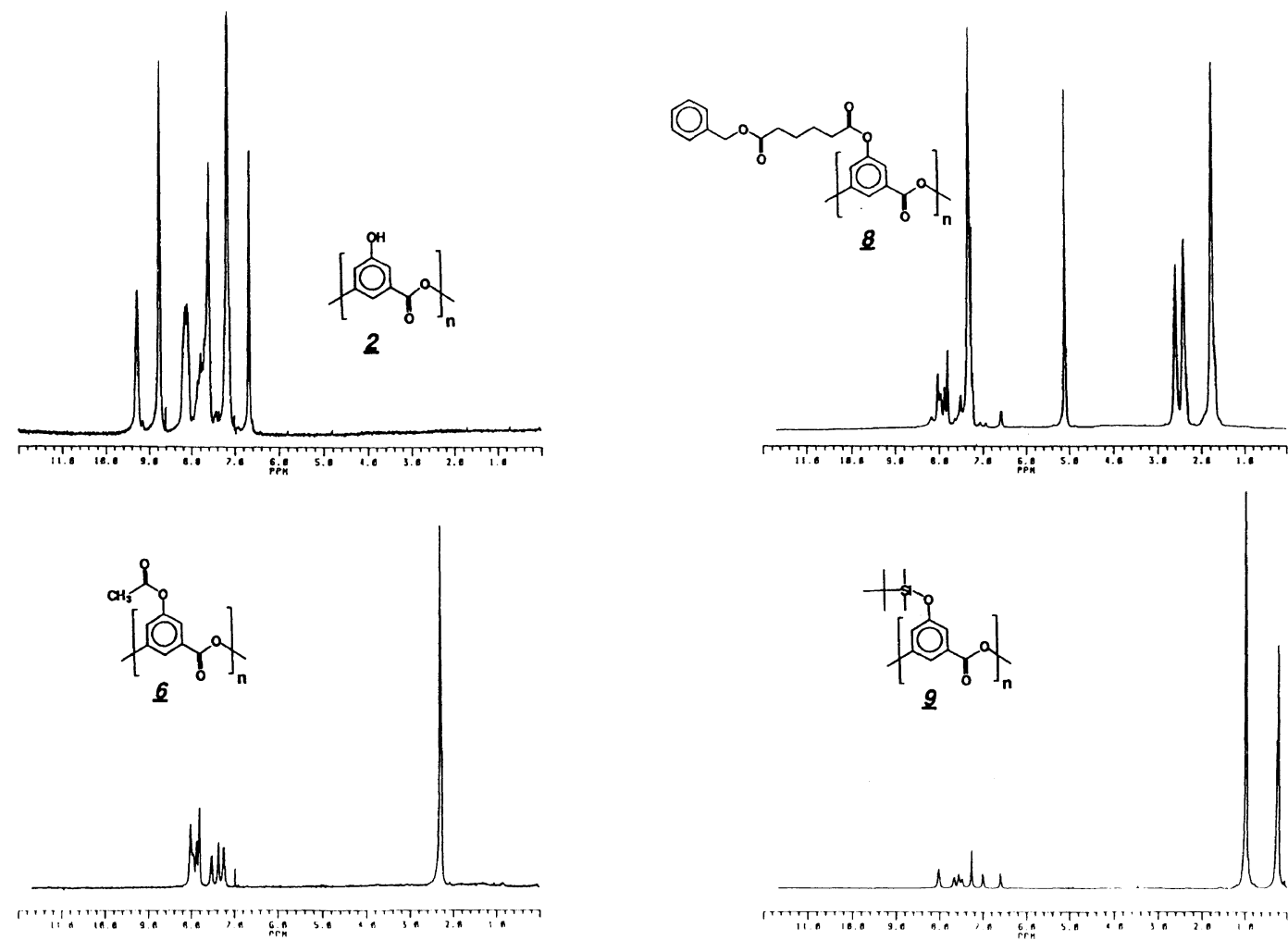

controllable by the reaction conditions, the degree of branching ${ }^{3}$ remains constant at approximately $60 \%$. This value was determin-

Table III. Molecular weight data from GPC with multi-angle laser light scattering and polystyrene standards for phenolic-terminal hyperbranched polyesters and their corresponding functionalized products in which the polar phenols are "capped"

\begin{tabular}{cccc}
\hline \multirow{2}{*}{$\begin{array}{c}\text { Starting } \\
\text { polymer } \\
M_{w}{ }^{\mathrm{a}}\end{array}$} & \multicolumn{3}{c}{ OH-Functionalized polymer } \\
\cline { 2 - 4 } & Functional group & $M_{w}{ }^{\mathrm{b}}$ & $M_{w} / M_{n}{ }^{\mathrm{b}}$ \\
\hline 30000 & $\mathrm{OCH}_{3}$ & 32000 & 4.0 \\
32000 & $\mathrm{OSi}\left(\mathrm{CH}_{3}\right)_{3}$ & 41000 & 2.0 \\
42000 & $\mathrm{O}_{2} \mathrm{CCH}_{3}$ & 46000 & 2.6 \\
60000 & $\mathrm{O}_{2} \mathrm{C}\left(\mathrm{CH}_{2}\right)_{4} \mathrm{CO}_{2} \mathrm{Bn}$ & 75000 & 3.1 \\
\end{tabular}

a MALLS in THF with $\mathrm{d} n / \mathrm{d} c=0.240$.

${ }^{b}$ GPC based on polystyrene standards.

Figure 1. ${ }^{1} \mathrm{H}$ NMR $(300 \mathrm{MHz})$ spectra of the phenolic terminated hyperbranched polyester, 2, and products, $\mathbf{6}, \mathbf{7}$, and $\mathbf{8}$, from modification reactions. 
ed by ${ }^{1} \mathrm{H}$ NMR analysis of the aromatic protons, and confirmed by integration data for the phenolic protons (exchangeable with $\mathrm{D}_{2} \mathrm{O}$ ) at 8.75 and $9.25 \mathrm{ppm}$ of the terminal diphenolic monomer units and linear monophenolic units, respectively. A representative ${ }^{1} \mathrm{H}$ NMR spectrum is shown in Figure 1.

The ${ }^{1} \mathrm{H}$ NMR spectra of compounds $\mathbf{6 , 8}$, and 9, shown in Figure 1, confirm the complete protection of the hydroxyl groups of the hyperbranched polyester. Comparison of the integration values of the protons for the aromatic monomer units with the protons of the functional groups gives the extent of modification of the chain ends. The functionalization reactions were also monitored by ${ }^{13} \mathrm{C}$ NMR and infrared spectroscopy. It is interesting to note the increased symmetry of the monomeric subunits upon esterification, as evidenced by the observation of fewer and sharper peaks in the ${ }^{13} \mathrm{C}$ NMR spectrum of 6 .

As has been found for dendritic macromolecules and other hyperbranched systems, the functionality of the chain ends dramatically affects the properties of these hyperbranched polyesters. The phenolic terminated products, $\mathbf{2}$, are only soluble in polar solvents, such as methanol, tetrahydrofuran, acetone, DMSO, and NMP, while the chain end modified hyperbranched polyesters are also soluble in solvents such as chloroform, dichloromethane, and toluene.

The thermal properties, including glass transition and thermal decomposition temperature were found to be very dependent on the nature of the chain ends (Scheme 3). Surprisingly, the $T_{\mathrm{g}}$ of 8 is only $6^{\circ} \mathrm{C}$, which suggests that the flexible alkyl units are distributed throughout the structure and act as plasticizers for the aromatic hyperbranched polyester. The variation in $T_{\mathrm{g}}$ values (Scheme 3) of the other products coincide with the rigidity and polarity of the phenol protecting groups. Weight losses observed in thermogravimetric analysis measurements were in rough agreement with the nature and composition of the functionalized hyperbranched materials. For example, the acetate group of $\mathbf{6}$ constitutes $33 \%$ of the total monomeric molecular weight of $178 \mathrm{amu}$, and TGA gives $37 \%$ weight loss occurring from 305 to $415^{\circ} \mathrm{C}$ with the remaining $63 \%$ decomposing between 415 $540^{\circ} \mathrm{C}$. Similarly, the adipic acid monobenzyl ester chain end unit of 8 constitutes $62 \%$ of the total monomeric unit molecular weight of $354 \mathrm{amu}$, and TGA shows $57 \%$ weight loss from 280 to $395^{\circ} \mathrm{C}$ with the remaining $43 \%$ decomposition occurring between 395 $545^{\circ} \mathrm{C}$.

\section{EXPERIMENTAL}

\section{General Directions}

Glass transition temperatures were measured by differential scanning calorimetry using a Mettler DSC 30 low temperture cell coupled to a TC10A TA processor. Heating rates were $10 \mathrm{~K} \mathrm{~min}^{-1} . T_{g}$ was taken as the midpoint of the inflection tangent. Thermogravimetric analyses were measured on a Mettler TG50 thermobalance at $20 \mathrm{~K} \mathrm{~min}^{-1}$ heating rate. Data analysis for both DSC and TGA was done with Mettler TA72 software. Infrared spectra were recorded on a Nicolet IR/44 spectrophotometer as thin films on $\mathrm{NaCl}$ disks. ${ }^{1} \mathrm{H}$ NMR spectra were recorded on solutions in $d_{6}$-acetone or $\mathrm{CDCl}_{3}$ on a Bruker WM300 $(300 \mathrm{MHz})$ spectrometer with the solvent proton signals as standard. ${ }^{13} \mathrm{C}$ NMR spectra were recorded at $75 \mathrm{MHz}$ on a Bruker WM300 spectrometer with the solvent carbon signal as internal standard. Size exclusion chromatography was carried out with a Hewlett Packard series 1050 autoinjector, Waters 590 programmable HPLC pump, and three Polymer Laboratories PL gel $10 \mu \mathrm{m}$ mixed bed columns connected to a Wyatt Technology Corporation DAWN ${ }^{\circledR}$ F Laser Photometer and then a Waters 410 Differential Refractometer; data analysis was performed with ASTRA software, version 2.02 and EASI (Wyatt); $\mathrm{d} n / \mathrm{d} c$ measurements were done on a Wyatt Optilab 903 
Refractometer.

Trimethylsilyl 3,5-Bis(trimethylsiloxy)benzoate (4)

A mixture of 3,5-dihydroxybenzoic acid 3 $(129 \mathrm{~g}, 0.838 \mathrm{~mol})$ and hexamethyldisilazane $(360 \mathrm{ml}, 275 \mathrm{~g}, 1.70 \mathrm{~mol})$ was heated at reflux under nitrogen for $6 \mathrm{~h}$ and stirred at room temperature for $3 \mathrm{~h}$. The reaction mixture was then evaporated to dryness and the crude product purified by fractional distillation, and the fraction boiling at $100-104^{\circ} \mathrm{C}(0.015$ $\mathrm{mmHg}$ ) being collected, to give the trimethylsilyl ester 4 as a colorless oil $(292 \mathrm{~g}, 94 \%):{ }^{1} \mathrm{H}$ $\operatorname{NMR}\left(\mathrm{CDCl}_{3}\right) \delta 0.26\left(\mathrm{~s}, 18 \mathrm{H}, \operatorname{ArOSi}\left(\mathrm{CH}_{3}\right)_{3}\right)$, $0.37\left(\mathrm{~s}, 9 \mathrm{H}, \mathrm{CO}_{2} \mathrm{Si}\left(\mathrm{CH}_{3}\right)_{3}\right), 6.52(\mathrm{t}, 1 \mathrm{H}, J=$ $2 \mathrm{~Hz}, \operatorname{Ar} H)$, and $7.12(\mathrm{~d}, 2 \mathrm{H}, J=2 \mathrm{~Hz}, \operatorname{Ar} H)$ ppm.

\section{3,5-Bis(trimethylsiloxy)benzoyl Chloride (1)}

To a solution of the trimethylsilyl ester 4 $(152 \mathrm{~g}, 0.410 \mathrm{~mol})$ in dry benzene $(200 \mathrm{ml})$ was added freshly distilled thionyl chloride $(36 \mathrm{ml}$, $59 \mathrm{~g}, 0.49 \mathrm{~mol}$ ) followed by $N, N$-dimethylformamide ( 5 drops). The reaction mixture was then heated at reflux under nitrogen for $14 \mathrm{~h}$, cooled, and then filtered through a short column of alumina ( $\mathrm{Ar}$ atmosphere). The solution was then evaporated to dryness and the crude acid chloride purified by Kugelrohr distillation at $100-120^{\circ} \mathrm{C}(0.15 \mathrm{mmHg})$ to give the acid chloride as a colorless oil $(97 \mathrm{~g}, 75 \%)$ : ${ }^{1} \mathrm{H} \mathrm{NMR}\left(\mathrm{CDCl}_{3}\right) \delta 0.28\left(\mathrm{~s}, 18 \mathrm{H}, \mathrm{OSi}\left(\mathrm{CH}_{3}\right)_{3}\right.$, $6.63(\mathrm{t}, 1 \mathrm{H}, J=2 \mathrm{~Hz}, \operatorname{Ar} H)$, and $7.20(\mathrm{~d}, 2 \mathrm{H}$, $J=2 \mathrm{~Hz}, \mathrm{Ar} H) \mathrm{ppm} ;{ }^{13} \mathrm{C} \mathrm{NMR}\left(\mathrm{CDCl}_{3}\right) \delta 0.14$, $110.60,116.23,119.11,134.89,137.72$, and $156.46 \mathrm{ppm}$.

Polymerization of 3,5-Bis(trimethylsiloxy)benzoyl Chloride (2)

A mixture of the monomer, 3,5-Bis(trimethylsiloxy)benzoyl chloride $1(2.00 \mathrm{~g}, 6.32$ mmol) and the catalyst (either trimethylamine hydrochloride or $N, N$-dimethylformamide in the desired molar percentage), in a round bottom flask equipped with a mmagnetic stirrer and under a stream of nitrogen, were placed into a hot oil bath equilibrated to the desired temperature. The reaction mixture became more viscous and usually solidified over time. After the desired reaction time, the reaction mixture was removed from the hot oil bath, tetrahydrofuran (THF) (ca. $10 \mathrm{ml}$ ) was added, and the THF solution was added to methanol $(200 \mathrm{ml})$. The methanol was removed in vacuo. The residue was dissolved in THF and precipitated into diethyl ether to remove the low molecular weight impurities. This precipitate was collected by suction filtration or decantation (depending on its consistency), dissolved in THF and precipitated into hexanes. The white to light brown (depending on reaction temperature) precipitate was collected by suction filtration and dried under reduced pressure. $T_{\mathrm{g}} 197^{\circ} \mathrm{C}$; IR $3500-2900$, $1744,1660,1595,1449,1298,1188,1134$, $1082 \mathrm{~cm}^{-1} ;{ }^{1} \mathrm{H}$ NMR $\left(\mathrm{CDCl}_{3}\right) \delta 6.60-6.80$, $7.05-7.40,7.47-7.88,7.96-8.34,8.6-9.0$, 9.2-9.5 ppm; ${ }^{13} \mathrm{C}$ NMR $\left(\mathrm{CDCl}_{3}\right) \delta 109$ $109.5,115-116,121.5-123,131.5-132.5$, $152-153,159-159.5,163.5,164.1,164.13$, $164.77,164.87 \mathrm{ppm}$.

Preparation of Hyperbranched Polymer in the Presence of the Capping Agent 4-tertButylbenzoyl Chloride

3,5-Bis(trimethylsiloxy)benzoyl chloride 1 $(1.0 \mathrm{~g}, 3.2 \mathrm{mmol}), 4$ - $t$-butylbenzoyl chloride $(0.65 \mathrm{~g}, 3.3 \mathrm{mmol})$ and trimmethylamine hydrochloride $(0.003 \mathrm{~g}, 0.03 \mathrm{mmol})$, in a $25 \mathrm{ml}$ round bottom flask equipped with a magnetic stirred and $\mathrm{N}_{2}$ bubbler, were placed into a $195^{\circ} \mathrm{C}$ oil bath. After $2 \mathrm{~h}$, the reaction mixture was allowed to cool, and then THF $(10 \mathrm{ml})$ was added. The THF solution was precipitated into methanol to yield the $t$-butylbenzoyl terminated hyperbranched polyester, $\mathbf{5}$, as an off-white powder and containing $86 \% t$ butylbenzoyl chain ends $[0.72 \mathrm{~g}, 82 \%$ (based on $86 \% t$-butylbenzoyl groups), $M_{w}=15000$, $M_{n}=6700$, by GPC based on polystyrene standards]; $T_{\mathrm{g}} 168^{\circ} \mathrm{C}$; IR $3600-3300,3100$, 
2964, 2907, 2870, 1746, 1599, 1445, 1260, 1186 , 1132, 1067, 1015, 999, $756 \mathrm{~cm}^{-1} ;{ }^{1} \mathrm{H}$ NMR $\left(\mathrm{CDCl}_{3}\right) \delta 1.0-1.5\left(\right.$ broad s, $\left.9 \mathrm{H}\left(\mathrm{CH}_{3}\right)_{3} \mathrm{C}-\right)$, 6.7-7.1, 7.2-7.6, 7.7-8.2 (broad s, broad s, broad $\mathrm{d}, 7.2 \mathrm{H}$ integration, aromatic $\mathrm{H}$ of $t$ butylbenzoyl groups and functionalized monomer units $(7 \mathrm{H}$ total), and unfunctionalized monomer units (3H/unit)) ppm; ${ }^{13} \mathrm{C}$ NMR $\left(\mathrm{CDCl}_{3}\right) \delta 34.7,46,3,119.9,120.8,125.1,127.1$, $130.0,132.7,151.4,154.7,162.8,162.9 \mathrm{ppm}$.

\section{Modification of the Free Phenolic Hydroxyls of 2}

Acetyl (6). To a solution of phenol terminated hyperbranched polyester $2(0.053 \mathrm{~g}, 0.39$ mmol repeat unit, $M_{w}=42000$, by MALLS) and triethylamine $(0.27 \mathrm{ml}, 0.20 \mathrm{~g}, 2.0 \mathrm{mmol}, 5$ eq) in THF $(10 \mathrm{ml})$ at room temperature under $\mathrm{N}_{2}$ was added acetyl chloride $(0.14 \mathrm{ml}, 0.15 \mathrm{~g}$, $1.9 \mathrm{mmol}, 5 \mathrm{eq})$ via syringe which caused the reaction mixture to become a white slurry. The reaction mixture was stirred at room temperature under $\mathrm{N}_{2}$ overnight, filtered, concentrated in vacuo, and precipitated into methanol to yield 6 as an off-white powder $(0.030 \mathrm{~g}, 43 \%$, $M_{w}=46000, M_{n}=18000$, by GPC based on polystyrene standards) with $100 \%$ conversion of the phenolic chain ends as determined by ${ }^{1} \mathrm{H}$ NMR. $T_{\mathrm{g}} 133^{\circ} \mathrm{C}$; IR 3096, 2950, 1750, $1595,1455,1391,1294,1197,1142,1098$, $1039 \mathrm{~cm}^{-1} ;{ }^{1} \mathrm{H}$ NMR $\left(\mathrm{CDCl}_{3}\right) \delta 2.2-2.5$ (broad s, $\mathrm{CH}_{3} \mathrm{CO}_{2}-$ ), 7.2, 7.33, 7.5, 7.8, 7.87, 7.92, 7.98 (each broad $\mathrm{s}$, aromatic $\mathrm{H}$ of monomer units) ppm; ${ }^{13} \mathrm{H}$ NMR $\left(\mathrm{CDCl}_{3}\right)$ 20.93, 120.8, 121.2, 103.8, 131.0, 131.2, 151.2, $151.3,162.7,162.8,168.6 \mathrm{ppm}$ : TGA: 305 $415^{\circ} \mathrm{C}, 37 \%$ wt. loss; $415-540^{\circ} \mathrm{C}, 63 \%$ we. loss.

Esterification with Adipic acid Monobenzyl Ester (8)

To a solution of phenol-terminated hyperbranched polyester $2(0.10 \mathrm{~g}, 0.74 \mathrm{mmol}$ repeat unit, $M_{w}=42000$, by MALLS $)$ in THF $(25 \mathrm{ml})$ at room temperature under $\mathrm{N}_{2}$ was added the monobenzylester of adipic acid $7(0.35 \mathrm{~g}, 1.5$ mmol, $2.0 \mathrm{eq}$ ), followed by dropwise addition of dicyclohexycarbodiimide $(0.33 \mathrm{~g}, 1.6$ mmol, $2.2 \mathrm{eq})$ in THF $(10 \mathrm{ml})$ and then $N, N$ dimethylaminopyridine $(0.009 \mathrm{~g}, 0.074 \mathrm{mmol}$, $0.1 \mathrm{eq})$ in THF $(2 \mathrm{ml})$. The reaction mixture was stirred at room temperature under $\mathrm{N}_{2}$ for $20 \mathrm{~h}$, during which time, a precipitate of dicyclohexylurea formed. The reaction mixture was filtered, concentrated in vacuo, and precipitated into methanol to yield $8(0.16 \mathrm{~g}$, $59 \%, M_{w}=53000, M_{n}=20000$, by GPC based on polystyrene standards) with $100 \%$ conversion of the phenolic chain ends as determined by ${ }^{1} \mathrm{H}$ NMR. Upon drying of the precipitate, the product change from an off-white opaque solid to a light brown viscous oil. $T_{\mathrm{g}} 6^{\circ} \mathrm{C}$; IR $3100-2830,1740,1595,1443,1281$, 1183, 1130, 1082, 997, $754 \mathrm{~cm}^{-1} ;{ }^{1} \mathrm{H}$ NMR $\left(\mathrm{CDCl}_{3}\right) \delta 1.75$ (broad s, $\left.-\mathrm{CH}_{2} \mathrm{CH}_{2}-\right), 2.4,2.6$ (each broad s, 2x- $\mathrm{CH}_{2} \mathrm{CO}_{2}-$ ), 5.1 (broad $\mathrm{s}, \mathrm{PhCH}_{2} \mathrm{O}_{2} \mathrm{C}-$ ) $, 6.55,6.9,7.05,7.5,7.8$, $7.88,7.93,8.0,8.15$ (each broad s, aromatic $\mathrm{H}$ of monomer units), 7.15-7.45 (broad s, $\left.\mathrm{Ph} \mathrm{HCH}_{2} \mathrm{O}_{2} \mathrm{C}-\right)$ ppm; ${ }^{13} \mathrm{C}$ NMR $\left(\mathrm{CDCl}_{3}\right) \delta$ $24.1,24.3,66.2,120.8,121.2,128.1,128.5$, $130.5-131.2,136.0,151.2-151.3,162.7-$ $162.8,170.9,172.9$ ppm; TGA: $280-395^{\circ} \mathrm{C}$, $57 \%$ wt. loss; $395-550^{\circ} \mathrm{C}, 43 \%$ wt. loss.

t-Butyl-dimethylsilyl (9) To a solution of phenol terminated hyperbranched polyester 2 $\left(M_{w}=42000,0.044 \mathrm{~g}, 0.32 \mathrm{mmol}\right.$ repeat unit) in THF $(5 \mathrm{ml})$ at room temperature under $\mathrm{N}_{2}$ was added $N$-( $t$-butyldimethylsilyl)- $N$-methyltrifluoroacetamide $(0.16 \mathrm{ml}, 0.16 \mathrm{~g}, 0.66 \mathrm{mmol}, 2.1$ eq) via syringe. The reaction mixure was stirred at room temperature under $\mathrm{N}_{2}$ overnight, filtered, concentrated in vacuo, and precipitated into methanol $(25 \mathrm{ml})$ to yield 9 as an off-white powder $\left(0.071 \mathrm{~g}, 89 \%, M_{w}=49000, M_{n}=\right.$ 19000 , by GPC based on polystyrene standards) with $100 \%$ conversion of the phenolic chain ends as determined by ${ }^{1} \mathrm{H}$ NMR. $T_{\mathrm{g}}$ $103^{\circ} \mathrm{C}$; IR 3090, 2957, 2932, 2895, 2861, 1750 , 1591, 1445, 1341, 1261, 1188, 1140, 1080, 1028, $1005,837,783 \mathrm{~cm}^{-1} ;{ }^{1} \mathrm{H} \mathrm{NMR}\left(\mathrm{CDCl}_{3}\right) \delta 0.25$, 0.3 (each broad $\mathrm{s},\left(\mathrm{CH}_{3}\right)_{2} \mathrm{Si}-$ of di- and 
mono-terminating (linear) monomer units, respectively), 1.0 (broad $\mathrm{s},\left(\mathrm{CH}_{3}\right)_{3} \mathrm{CSi}-$ ), 6.6, $7.0,7.25,7.45,7.5,7.65,8.0$ (each broad $\mathrm{s}$, aromatic $\mathrm{H}$ of monomer units) ppm; ${ }^{13} \mathrm{C} \mathrm{NMR}$ $\left(\mathrm{CDCl}_{3}\right) \delta-4.39,18.22,25.66,115.2,116.6$, $117.6,117.9,119-120,121-122,130.5-$ $131.5, \quad 151-152,156.9$ ppm; TGA: 285 $355^{\circ} \mathrm{C}, 10 \%$ wt. loss; $355-460^{\circ} \mathrm{C}, 35 \%$ wt. loss; $460-590^{\circ} \mathrm{C}, 35 \%$ wt. loss; $20 \%$ mass remaining after $590^{\circ} \mathrm{C}$.

Methyl (10) To a solution of phenol terminated hyperbranched polyester $2\left(M_{w}=\right.$ $30000,0.071 \mathrm{~g}, 0.52 \mathrm{mmol}$ repeat unit) in THF $(5 \mathrm{ml})$ at room temperature under $\mathrm{N}_{2}$ was added an ethereal solution containing diazomethane ( $3 \mathrm{ml}, 0.9 \mathrm{mmol}, 1.7 \mathrm{eq}$ ). Effervescence of $\mathrm{N}_{2}$ was observed, and the reaction mixture became cloudy. The reaction mixture was stirred at room temperature under $\mathrm{N}_{2}$ overnight, with most of the precipitate redissolving. A small amount of acetic acid was added to quench remaining diazomethane, and then the reaction mixture was precipitated into heaxanes to yield $\mathbf{1 0}$ as an off-white powder $\left(0.061 \mathrm{~g}, 78 \%, M_{w}=32000, M_{w} / M_{n}=4.0\right.$, by GPC based on polystyrene standards) with $100 \%$ conversion of the phenolic chain ends as determined by ${ }^{1} \mathrm{H}$ NMR. IR $3200-2850$, 1743, 1596, 1463, 1429, 1334, 1293, 1201, 1181 , $1142,1047 \mathrm{~cm}^{-1} ;{ }^{1} \mathrm{H}$ NMR $\left(\mathrm{CDCl}_{3}\right) \delta 3.82$ (broad s, $\mathrm{CH}_{3}$ ), 6.69, 7.07, 7.30, 7.49, 7.51, 8.01 (each broad s, aromatic $\mathrm{H}$ of monomer units) ppm.

Acknowledgments. Financial support for this research by the National Science Foundation (DMR 9224421) and fellowship support from the US Department of Education (KLW) is acknowledged with thanks. This work made use of the Cornell University Materials Science Center supported by the National Science Foundation (DMR 9121654). The authors also thank Dr. S. R. Turner and Dr. U. Kumar for useful discussions.

\section{REFERENCES}

1. Y. H. Kim and O. W. Webster, J. Am. Chem. Soc., 112, 4592 (1990).

2. Y. H. Kim and O. W. Webster, Macromolecules, 25(21), 5561 (1992).

3. C. J. Hawker, R. Lee, and J. M. J. Fréchet, J. Am. Chem. Soc., 113, 4583 (1991).

4. B. I. Voit, S. R. Turner, and T. H. Mourey, Polym. Prepr., J. Am. Chem. Soc., Div. Polym. Chem., 184 (1992).

5. H. R. Kricheldorf, Q. Z. Zeng, and G. Schwarz, Polymer, 23, 1821 (1982).

6. K. E. Uhrich, C. J. Hawker, and J. M. J. Fréchet, Macromolecules, 25, 4583 (1992).

7. T. M. Miller, T. X. Neeman, E. W. Kwock, and S. M. Stein, J. Am. Chem. Soc., 115, 356 (1993).

8. F. Chu and C. J. Hawker, Polym. Bull., 30, 265 (1993)

9. Y. H. Kim, J. Am. Chem. Soc., 114, 4947 (1992).

10. L. J. Mathias and T. W. Carothers, J. Am. Chem. Soc., 113, 4043 (1991).

11. M. Suzuki, A. Ii, and T. Saegusa, Macromolecules, 25, 7071 (1992).

12. C. J. Hawker and J. M. J. Fréchet, J. Am. Chem. Soc., 114, 8405 (1992).

13. H. R. Kricheldorf and G. Schwarz, Makromol. Chem., 184, 475 (1983).

14. S. R. Turner, B. I. Voit, and T. H. Mourey, Macromolecules, 26, 4617 (1993).

15. A. Hassner and V. Alexanian, Tetrahedron Lett., 4475 (1978); S. Neelakantan, R. Padmasani, and T. R. Seshadri, Tetrahedron, 3531 (1965).

16. K. L. Wooley, J. M. J. Eréchet, and C: J. Hawker, Polymer, in press.

17. C. J. Hawker and J. M. J. Fréchet, J. Am. Chem. Soc., 112, 7638 (1990). 